\title{
Affected skeletal growth but normal bone mineralization in rat offspring after prenatal dexamethasone exposure
}

\author{
D Swolin-Eide ${ }^{1,2}$, J Dahlgren ${ }^{2,3}, \mathrm{C} \mathrm{Nilsson}^{3}$, \\ K Albertsson Wikland ${ }^{2}$, A Holmäng ${ }^{3}$ and C Ohlsson ${ }^{1}$ \\ ${ }^{1}$ Research Center for Endocrinology and Metabolism, Department of Internal Medicine, Sahlgrenska University Hospital, S-413 45 Göteborg, Sweden \\ ${ }^{2}$ Pediatric Growth Research Center, Institute for the Health of Women and Children, Sahlgrenska University Hospital, S-416 85 Göteborg, Sweden \\ ${ }^{3}$ Wallenberg Laboratory, Sahlgrenska University Hospital, S-413 45 Göteborg, Sweden \\ (Requests for offprints should be addressed to D Swolin-Eide, Research Center for Endocrinology and Metabolism, Department of Internal Medicine, \\ Gröna stråket 8, Sahlgrenska University Hospital, S-41345 Göteborg, Sweden; Email: diana.swolin@medic.gu.se)
}

\begin{abstract}
Events occurring early in life or prenatally are able to play important roles in the pathogenesis of diseases in adult life. Different sorts of stress or hormonal influences, during particular periods of pregnancy, may result in persisting or transient changes in physiology. Glucocorticoids are used for the treatment of a variety of diseases, to promote organ maturation and to prevent preterm delivery. Glucocorticoids are also known to affect skeletal growth and adult bone metabolism. The aim of the present study was to investigate whether exposure to dexamethasone (Dex) during fetal life has any effect on skeletal growth and/or bone mineral density in adult rat offspring.

Pregnant rats were given injections of either Dex $(100 \mu \mathrm{g} / \mathrm{kg})$ or vehicle on days 9, 11 and 13 of gestation. Dex-exposed male but not female rat offspring showed
\end{abstract}

transient increases in crown-rump length and tibia and femur lengths at 3-6 weeks of age. In contrast, the cortical bone dimensions were altered in 12-week-old female but not male Dex-exposed offspring. The areal bone mineral densities of the long bones and the spine, as determined by dual X-ray absorptiometry, and trabecular as well as cortical volumetric bone mineral density, as measured using peripheral quantitative computerized tomography, were unchanged in both male and female Dex-exposed offspring.

In conclusion, prenatal Dex exposure affects skeletal growth in a gender-specific manner, while the mineralization of bones is unaffected in both male and female offspring.

Journal of Endocrinology (2002) 174, 411-418

\section{Introduction}

It has been shown that events occurring early in life or prenatally are able to play important roles in the pathogenesis of adult disease in both humans and animals (Barker et al. 1993, Benediktsson et al. 1993). The process whereby a stimulus or insult at a sensitive or critical period of development has long-term effects is termed 'programming' (Lucas 1991). Dexamethasone (Dex) is a potent synthetic glucocorticoid lacking mineralocorticoid activity, and it passes through the placenta without being inactivated by the enzyme $11 \beta$-hydroxysteroid dehydrogenase. Exposure to Dex late in pregnancy has been claimed to result in a reduced birth weight, and in hyperinsulinaemia and hypertension in adulthood (Benediktsson et al. 1993, NIH 1995). A recent clinical study suggests that low birth weight is associated with lower adult bone and muscle mass which indicate that the risk of osteoporosis in later life might be programmed by genetic or environmental influences during gestation (Gale et al. 2001). Further- more, a low birth weight and leanness at birth have been shown to be associated with insulin resistance in children and adolescents (Ornoy \& Altshuler 1976, Hofman et al. 1997, Robinson et al. 2000). A recent study has shown that prenatal exposure to Dex leads to increased fat depots in the adult rat. One of the possible mechanisms involved is programming of the fetal hypothalamo-pituitary-adrenal (HPA) axis (Matthews 2000). The HPA axis, which is central to the integration of the individual's endocrine and behavioural response to stress, appears to be highly sensitive to an excess of glucocorticoids during development (Clark 1998).

Glucocorticoids are widely used to treat inflammatory diseases, asthma, and as immunosuppressives. High endogenous levels of cortisol are seen during infections and stressful events. Furthermore, 10\% of pregnant women in North America and Europe are treated with synthetic glucocorticoids between weeks 24 and 34 of gestation to promote fetal lung maturation in fetuses at risk of being delivered prematurely (Matthews 2000). Long-term 
therapy with high doses of glucocorticoids has been shown to suppress skeletal growth in childhood (Blodgett et al. 1956). Possible mechanisms for this might include a central mechanism through the somatotrophic hormone axis and direct effects on the growth plate by suppression of chondrocyte proliferation (Klaus et al. 2000).

Glucocorticoids also have profound effects on adult bone metabolism, and prolonged exposure to excessive amounts of glucocorticoids results in osteoporosis (Cushing 1932). However, the exact mechanism for this effect remains to be elucidated. Fetal rat osteoblasts express receptors for glucocorticoids (Chen \& Feldman 1979) and a direct effect on bone formation is therefore possible. High levels of glucocorticoids inhibit bone formation via complex direct and indirect mechanisms, including inhibition of osteoblastic cell replication, decreased collagen expression and increased collagenase expression (Canalis 1996). Furthermore, high levels of glucocorticoids also increase bone resorption (Hofbauer et al. 1999). Increasing evidence suggests that a mechanism for glucocorticoidinduced bone diseases arises from changes in osteoblast and osteocyte numbers due to apoptosis of these cells (Hughes \& Boyce 1997, Weinstein et al. 1998, Weinstein \& Manolagas 2000).

The aim of the present study was to investigate whether glucocorticoids can cause long-lasting effects on skeletal growth and/or mineralization of bones in rat offspring after early prenatal exposure.

\section{Materials and Methods}

\section{Animals}

Timed-pregnant nulliparous Wistar rats (B\&K Universal, Sollentuna, Sweden) were housed one animal per cage until parturition, under controlled conditions, at a temperature of $21 \pm 1{ }^{\circ} \mathrm{C}$, humidity of $55-65 \%$ and lights on from 0700 to $1900 \mathrm{~h}$. They received a commercial rat chow (containing $18.7 \%$ protein, $4.7 \%$ fat and $63 \%$ carbohydrates, with a sufficient supply of vitamins and minerals) (B\&K Universal). Tap water was available ad libitum. Pups were raised with a lactating mother until 4 weeks of age. Thereafter, they lived in cages, with three to four animals from the same group per cage. The study was approved by the Animal Ethic Committee of Göteborg University.

\section{Dams and litters}

Dams were randomly divided and given i.m. injections on days 9, 11 and 13 of gestation of $100 \mu \mathrm{g} / \mathrm{kg}$ Dex (Merck Sharp \& Dohme BV, Harlem, The Netherlands) $(n=5)$. Control dams $(n=5)$ were injected i.m. with physiological saline. The three time-points for injections were chosen to cover a sensitive period of early fetal brain development (Paxinos et al. 1991) and the dose was chosen to suppress corticosterone levels (Mosier et al. 1981).
Blood samples from the mothers were collected $4 \mathrm{~h}$ after injection, to determine corticosterone concentrations. Gestation lasted for 22 days in all dams. One control dam did not deliver and one control dam delivered only four pups, which were excluded. Five Dex-exposed pups died within the first days of life, without any signs of infection. No gross abnormalities were observed in the pups exposed to Dex.

Litters were weighed at birth and placed with their dams within each experimental group. Male and female offspring were brought up together and each dam had equal numbers of pups (eight to ten), the litters being adjusted to contain approximately the same ratio of male/female pups. The pups were weaned at 4 weeks of age. Six offspring of each gender and group were killed by an overdose of anaesthesia at 6 weeks of age. The remaining offspring were kept until 10 weeks of age for male rats and 12 weeks of age for female rats. The gonads and the muscles of the hind limb (extensor digitorum longus, tibialis anterior and soleus muscles) were rapidly excised and weighed. Left femur, tibia and vertebra $\mathrm{L}_{6}$ were excised and stored in $70 \%$ ethanol until analysis.

\section{Body and tissue weights}

Total body weight and the weight of muscles and gonads were measured on a balance (PG 3001-S; Mettler Toledo, Greifensee, Switzerland). The body length, left femur, left tibia and the height of vertebra $\mathrm{L}_{6}$ were measured by the same person with a digital vernier calliper (Electronic Digital Calliper 0-150 mm, 0.01 mm accuracy, 30-4259; Clas Ohlsson AB, Insjön, Sweden).

\section{Food intake}

At 8-10 weeks of age, food consumption for each cage (three to four animals per cage) was recorded every second day for 20 days and calculated as food intake in grams per rat per day. All animals were presented with the same amount of food and their intake was measured the following day by subtracting the uneaten food plus spillage from the total food given (male cages: $\operatorname{dex} n=3$, controls $n=2$; female cages: dex $n=3$, controls $n=3$ ).

\section{Baseline hormone levels}

At 5-10 weeks of age, blood samples were collected from a nick in the tail after the rats had been fasted overnight. Samples were taken between 0800 and $1000 \mathrm{~h}$ on the same day to determine levels of leptin (week 8) and testosterone, $17 \beta$-estradiol and progesterone (weeks 9-10 in females, the day after oestrus, when these hormones are known to be low compared with the pro-oestrous phase). Vaginal smears were obtained daily between 8 and 10 
weeks of age, to determine the oestrous cycle. Corticosterone was analysed in the non-fasting state at 5 weeks of age (Smith et al. 1975).

\section{Hormone analysis}

Blood was collected in heparinized microtubes and centrifuged immediately in a microcentrifuge at $4{ }^{\circ} \mathrm{C}$. Testosterone was measured with a solid-phase RIA (CoatA-Count Total Testosterone; Diagnostic Products, Los Angeles, CA, USA); intra-assay coefficient of variation $(\mathrm{CV})<10 \%$, interassay $\mathrm{CV}<12 \%$ and detection level above 0.14 nmol/l. Progesterone was assayed with a commercially available ELISA (Biomar Diagnostic Systems, Marburg, Germany); intra-assay CV was $<9 \%$, interassay $\mathrm{CV}$ was $<10 \%$ and detection level was above $1.6 \mathrm{nmol} /$. $17 \beta$-Oestradiol was measured with an ultra-sensitive oestradiol RIA (Diagnostic Systems); intra-assay CV was $<9 \%$, interassay $\mathrm{CV}$ was $<12 \%$ and detection level was above $10 \mathrm{pmol} / \mathrm{l}$. Corticosterone was determined by RIA (RSL ${ }^{125}$ I corticosterone RIA; ICN Biomedicals, Costa Mesa, CA, USA); intra-assay CV was $<10 \%$, interassay $\mathrm{CV}$ was $<10 \%$ and detection level was above $25 \mathrm{ng} / \mathrm{ml}$. Leptin was determined by RIA (Rat Leptin RIA kit; Linco Research, St Louis, MO, USA); intra-assay CV was $<5 \%$, interassay CV was $<6 \%$ and detection level was above $0.5 \mathrm{ng} / \mathrm{ml}$. Serum insulin-like growth factor I (IGF-I) was measured by a double-antibody IGFbinding protein-blocked RIA (IGF-I, IGFBP blocked; Mediagnost, Tubingen, Germany); interassay $\mathrm{CV}$ was $<8 \%$, cross-reactivity with IGF-II was less than $0.05 \%$ and detection level was above $0 \cdot 16 \mathrm{ng} / \mathrm{ml}$. Serum osteocalcin levels were measured by an ELISA (Rat-MID osteocalcin ELISA; Osteometer BioTech A/S, Herlev, Denmark); intra-assay $\mathrm{CV}$ was $<8 \%$, interassay $\mathrm{CV}$ was $<10 \%$ and detection level was above $62 \mathrm{ng} / \mathrm{ml}$.

Bone mineral content (BMC) and areal bone mineral density (BMD; BMC $/ \mathrm{cm}^{2}$ ) were measured using pDEXA Sabre and Sabre Research software (both from Norland Medical Systems Inc., Fort Atkinson, WI, USA). Ex vivo measurements of femur, tibia and vertebra $\mathrm{L}_{6}$ were performed on excised bones placed on a $1 \mathrm{~cm}$ thick plexiglass table. All bones to be compared were measured in the same scan as previously described (Windahl et al. 1999). For dual X-ray absorptiometry (DXA) measurements, the interassay $\mathrm{CV}$ was less than $4 \%$.

\section{Peripheral quantitative computerized tomography ( $p Q C T$ )}

Computerized tomography was performed with the Stratec pQCT XCT Research M (software version 5·4B; Norland Medical Systems Inc.) operating at a resolution of $70 \mu \mathrm{m}$.

Mid-diaphyseal pQCT scans of femur and tibia were performed to determine the cortical volumetric BMD, the cortical cross-sectional area, the cortical thickness and the periosteal and endosteal circumferences. The middiaphyseal region of the femur and tibia in rats contains mostly cortical bone (Windahl et al. 1999).

Metaphyseal pQCT scans of left femur and tibia were performed to measure trabecular volumetric BMD. The scan was positioned in the metaphysis at a distance from the distal growth plate corresponding to $7 \%$ of the total length of the femur and $5 \%$ of the total length of the tibia (an area containing a central portion of trabecular bone). The trabecular bone region was defined by setting an inner threshold at $45 \%$ of the total area. The interassay CV values for the pQCT measurements were less than $2 \%$.

It should be emphasized that the DXA technique gives the areal BMD, whereas the pQCT gives the real/ volumetric BMD. Thus DXA gives the mineral content per area, not per volume. Therefore, a factor regulating the outer dimensions of a bone will affect the areal BMD (DXA) but not the volumetric BMD (pQCT).

\section{Growth plate width}

Right tibias and femurs from 6-week-old male offspring were fixed in $4 \%$ formaldehyde, embedded in paraffin, sectioned and stained with alcian blue/Van Gieson stain. The widths of the growth plates were measured using an image-processing system (Easy Image; Bergströms Instrument, Stockholm, Sweden) coupled to a microscope. An average of 60 growth plate measurements (six sections, ten measurements/section) was calculated for each tibia and femur.

\section{Statistical methods}

Distribution of variables are given as means \pm S.E.M. Student's $t$-test was used for comparison between the treatment groups and the control groups and a two-tailed $P$ value of $<0.05$ was considered significant.

\section{Results}

\section{Dams and litters}

The body weight of the dams increased throughout pregnancy and there was no significant difference in body weight between the two groups at any time-point (data not shown). To confirm that the Dex treatment was functioning, Dex-injected dams were analysed for serum corticosterone. This revealed suppressed serum corticosterone levels $4 \mathrm{~h}$ after injection, compared with basal levels and those in control dams (before first injection: Dex, $639 \pm 86 \mathrm{ng} / \mathrm{ml}$; controls, $503 \pm 80 \mathrm{ng} / \mathrm{ml}$; after second injection: Dex, $50 \pm 20 \mathrm{ng} / \mathrm{ml}$; controls, $371 \pm 73 \mathrm{ng} / \mathrm{ml} ; P<0 \cdot 01)$. Litter size for the Dex-exposed group was lower compared with the control group (Dex, $8 \cdot 6 \pm 0 \cdot 58$; controls, $12 \cdot 0 \pm 0 \cdot 58 ; P<0 \cdot 05)$. 
Body weight and skeletal growth

Because of difficulties in sexing pups before 2 weeks of age, pooled results are presented for male and female pups until 3 weeks of age, when the offspring were divided into females and males and body weight was measured every week (Table 1). There was no difference in body weights of newborn pups in the Dex-injected group compared with controls but the Dex-treated group was heavier at 2 weeks of age. Dex-treated male offspring were heavier from 3 to 5 weeks of age, and Dex-treated female offspring were heavier from 3 to 4 weeks of age compared with the control group (Table 1). This increase in weight was transient and not seen from weeks 6 to 12. Crown-rump length was measured during the first 5 weeks after birth. Dex-treated male offspring were significantly longer at weeks 3 and 5 (Table 2). No significant effect on crown-rump length was seen in Dex-treated female offspring except at 5 weeks of age, when the Dex-treated group was shorter than the control group.

The height of vertebra $\mathrm{L}_{6}$ and the lengths of the tibia and the femur were measured at 6 and 10 weeks of age (Table 3). No significant effect was observed in any group in the female offspring consistent with the lack of effect on body weight at these ages (data not shown). In male offspring, there was a significant increase at week 6 in the lengths of the tibia and femur in the Dex-treated group, similar to that seen for the crown-rump length at 5 weeks of age (Tables 2 and 3).

\section{Growth plate width}

As Dex-treated male rats showed increased tibia and femur lengths, the growth plate width was determined. Histological examination of the growth plate width revealed no difference between the male Dex-treated group and the male control group at 6 weeks of age (tibia: Dex, $204 \pm 4 \mu \mathrm{m}$; controls, $215 \pm 7 \mu \mathrm{m}$; femur: Dex, $185 \pm 6 \mu \mathrm{m}$; controls, $205 \pm 6 \mu \mathrm{m}$ ).

\section{Bone mineral status as determined by DXA and pQCT}

Areal BMD of the tibia, femur and spine were examined by DXA. No difference was seen between the Dextreated rats and control rats at 6 and 12 weeks of age for female rats and at 6 and 10 weeks of age for male rats. pQCT analysis was performed to investigate if there were any effects on cortical or trabecular bone, which cannot be separated by DXA analysis. Measurements of trabecular volumetric BMD in the metaphysis of the femur did not detect any significant effect of Dex treatment in either male or female offspring (Table 4) for female rats (data not shown for male rats). However, when analysing cortical bone parameters of the femurs, cortical thickness was significantly reduced in the Dex-treated female group at 12 weeks of age (Table 4). This reduction was associated with a significant increase in both periosteal and endosteal 
Table 2 Development of crown-rump length $(\mathrm{mm})$ from birth to 5 weeks of age. Values are means \pm S.E.M.

\begin{tabular}{|c|c|c|c|c|c|c|c|}
\hline & At birth & Week 1 & Week 2 & After sexing & Week 3 & Week 4 & Week 5 \\
\hline Control & & & & & & & \\
\hline \multirow[t]{2}{*}{$\begin{array}{l}\text { Female + male } \\
(n=30)\end{array}$} & $50 \cdot 7 \pm 0 \cdot 4$ & $68 \cdot 5 \pm 0 \cdot 5$ & $87 \cdot 2 \pm 0 \cdot 7$ & $\begin{array}{l}\text { Female } \\
(n=18)\end{array}$ & $105 \cdot 1 \pm 1 \cdot 2$ & $128 \cdot 0 \pm 1 \cdot 0$ & $144 \cdot 6 \pm 0 \cdot 5$ \\
\hline & & & & $\begin{array}{l}\text { Male } \\
(n=12)\end{array}$ & $104 \cdot 5 \pm 1 \cdot 2$ & $133 \cdot 0 \pm 0 \cdot 7$ & $148 \cdot 3 \pm 0 \cdot 3$ \\
\hline \multirow[t]{2}{*}{$\begin{array}{l}\text { Dex-treated } \\
\text { Female+male } \\
(n=35)\end{array}$} & $51 \cdot 0 \pm 0 \cdot 3$ & $68 \cdot 6 \pm 0 \cdot 6$ & $90 \cdot 1 \pm 0 \cdot 6^{* *}$ & $\begin{array}{l}\text { Female } \\
(n=19)\end{array}$ & $106 \cdot 0 \pm 0 \cdot 5$ & $127 \cdot 6 \pm 0 \cdot 5$ & $142 \cdot 4 \pm 0 \cdot 7^{*}$ \\
\hline & & & & $\begin{array}{l}\text { Male } \\
(n=16)\end{array}$ & $108 \pm 0 \cdot 7^{* *}$ & $131 \cdot 1 \pm 0 \cdot 8$ & $150 \cdot 9 \pm 0 \cdot 5^{\star \star \star}$ \\
\hline
\end{tabular}

From birth to 2 weeks of age, sex was not identified and data are therefore pooled together in Dex-treated or control offspring. Dex-treated offspring (male and female) are compared with controls (female and male) from birth to week 2; from weeks 3 to 5, Dex-treated females are compared with control females and control males are compared with Dex-treated males; ${ }^{*} P<0 \cdot 05,{ }^{* *} P<0 \cdot 01,{ }^{* * *} P<0 \cdot 001$ Dex vs control.

Table 3 Length of tibia, femur and height of vertebra $L_{6}$ in male rats and controls at 6 and 10 weeks of age. Values are means \pm S.E.M.

\begin{tabular}{|c|c|c|c|c|}
\hline & \multicolumn{2}{|c|}{6 Weeks of age } & \multicolumn{2}{|c|}{10 weeks of age } \\
\hline & $\begin{array}{l}\text { Control } \\
(n=6)\end{array}$ & $\begin{array}{l}\text { Dex } \\
(n=6)\end{array}$ & $\begin{array}{l}\text { Control } \\
(n=6)\end{array}$ & $\begin{array}{l}\text { Dex } \\
(n=10)\end{array}$ \\
\hline Vertebrae $\mathrm{L}_{6}(\mathrm{~mm})$ & $5 \cdot 10 \pm 0 \cdot 07$ & $5 \cdot 14 \pm 0 \cdot 06$ & $7 \cdot 31 \pm 0 \cdot 25$ & $7 \cdot 26 \pm 0 \cdot 06$ \\
\hline Tibia $(\mathrm{mm})$ & $29 \cdot 91 \pm 0 \cdot 22$ & $30 \cdot 91 \pm 0 \cdot 26^{*}$ & $37 \cdot 33 \pm 0 \cdot 17$ & $37 \cdot 61 \pm 0 \cdot 18$ \\
\hline Femur (mm) & $24 \cdot 91 \pm 0 \cdot 15$ & $25 \cdot 52 \pm 0.22^{*}$ & $32 \cdot 35 \pm 0 \cdot 23$ & $32 \cdot 02 \pm 0 \cdot 14$ \\
\hline
\end{tabular}

Table 4 Trabecular volumetric BMD and cortical bone parameters of femur as measured using pQCT for Dex-treated and control female offspring at 6 and 10 weeks of age. Values are means \pm S.E.M.

6 Weeks of age

\begin{tabular}{|c|c|}
\hline $\begin{array}{l}\text { Control } \\
(n=6)\end{array}$ & $\begin{array}{l}\text { Dex } \\
(n=6)\end{array}$ \\
\hline $0 \cdot 199 \pm 0 \cdot 022$ & $0 \cdot 186 \pm 0 \cdot 023$ \\
\hline $1 \cdot 158 \pm 0 \cdot 006$ & $1 \cdot 164 \pm 0 \cdot 005$ \\
\hline $3 \cdot 26 \pm 0 \cdot 11$ & $3 \cdot 32 \pm 0 \cdot 09$ \\
\hline $3 \cdot 78 \pm 0 \cdot 14$ & $3 \cdot 86 \pm 0 \cdot 11$ \\
\hline $0.43 \pm 0.02$ & $0.42 \pm 0.01$ \\
\hline $8.93 \pm 0 \cdot 10$ & $9 \cdot 22 \pm 0 \cdot 11$ \\
\hline $6 \cdot 23 \pm 0 \cdot 13$ & $6 \cdot 58 \pm 0 \cdot 11$ \\
\hline
\end{tabular}

12 weeks of age

\begin{tabular}{|c|c|}
\hline $\begin{array}{l}\text { Control } \\
(n=11)\end{array}$ & $\begin{array}{l}\text { Dex } \\
(n=12)\end{array}$ \\
\hline $0.452 \pm 0.041$ & $0 \cdot 386 \pm 0.022$ \\
\hline $1 \cdot 307 \pm 0 \cdot 006$ & $1 \cdot 311 \pm 0 \cdot 004$ \\
\hline $5 \cdot 47 \pm 0.09$ & $5 \cdot 42 \pm 0 \cdot 10$ \\
\hline $7 \cdot 15 \pm 0 \cdot 12$ & $7 \cdot 11 \pm 0 \cdot 13$ \\
\hline $0.65 \pm 0.01$ & $0.62 \pm 0.01^{*}$ \\
\hline $10 \cdot 42 \pm 0 \cdot 08$ & $10 \cdot 72 \pm 0.09^{*}$ \\
\hline $6 \cdot 32 \pm 0 \cdot 07$ & $6 \cdot 85 \pm 0 \cdot 10^{* *}$ \\
\hline
\end{tabular}

Metaphyseal trabecular BMD $\left(\mathrm{mg} / \mathrm{mm}^{3}\right)$

Cortical density $\left(\mathrm{mg} / \mathrm{mm}^{3}\right)$

Cortical area $\left(\mathrm{mm}^{2}\right)$

Cortical content $(\mathrm{mg} / \mathrm{mm})$

Cortical thickness $(\mathrm{mm})$

Cortical periosteal circumference $(\mathrm{mm})$

Cortical endosteal circumference $(\mathrm{mm})$

pQCT analyses were performed at 6 and 12 weeks of age. ${ }^{*} P<0 \cdot 05,{ }^{* *} P<0 \cdot 01$ (t-test).

circumferences (Table 4). In contrast, no significant effect on cortical bone parameters was found in male rats (data not shown).

\section{Serum parameters}

Leptin levels were increased at 8 weeks of age in Dextreated female offspring (Dex, 1.25 $\pm 0.07 \mathrm{ng} / \mathrm{ml}$; controls, $0.95 \pm 0.10 \mathrm{ng} / \mathrm{ml} ; \quad P<0.05)$. This was associated with an increase in adipose tissue at week 12 , although it did not reach statistical significance (parametrial fat: controls, $17.7 \pm 1.73 \mathrm{~g} / \mathrm{kg}$ body weight (b.w); Dex, $21.5 \pm 1.78 \mathrm{~g} / \mathrm{kg}$ b.w; retroperitoneal fat: controls,
$12 \cdot 6 \pm 1 \cdot 19 \mathrm{~g} / \mathrm{kg}$ b.w; Dex, $14 \cdot 6 \pm 1 \cdot 59 \mathrm{~g} / \mathrm{kg} \quad$ b.w.). Serum levels of IGF-I, corticosterone, testosterone, progesterone, oestradiol and osteocalcin were unchanged in Dex-treated animals compared with controls in both males and females.

\section{Organ weights and food intake}

The weights of gonads, muscles and adrenals were measured at 12 weeks of age in female rats and at 10 weeks of age in male rats. These weights did not differ between Dex-treated and control rats (data not shown). Furthermore, food intake was measured between 8 and 10 weeks 
of age; there was no difference in food intake between the Dex-treated group and the control group (data not shown).

\section{Discussion}

The programming hypothesis, whereby events early in life or during specific fetal periods have long-lasting effects later in life, is supported by human epidemiological data and animal models. These studies have confirmed that changes in the nutritional, metabolic and hormonal environment during both prenatal and postnatal periods of life may have profound effects on body composition, glucose tolerance, blood pressure and cardiovascular diseases (Lucas 1991, Benediktsson et al. 1993, NIH 1995, Dahlgren et al. 2001, Holmäng 2001). From a clinical point of view, it is important to examine the effects of glucocorticoids on different organ systems, as they are used antenatally to accelerate the maturation of fetal respiratory and cardiovascular systems when there is a risk of preterm delivery. Postnatally, glucocorticoids are used to prevent and treat respiratory distress syndrome. Also, pregnant women with a variety of diseases are treated with steroids. Currently, very little information is available on the impact of such treatment regimens. Previous studies regarding the effects of prenatal exposure to glucocorticoids have focused on metabolic or neuroendocrine effects and not on skeletal effects. This study was therefore undertaken to investigate whether prenatal exposure to glucocorticoids in rats has any effect on skeletal growth and adult bone tissue in offspring.

We demonstrate, for the first time, that prenatal Dex exposure affects skeletal growth. Dex-treated male but not female rats demonstrated a transient increase in crownrump length and long-bone length, indicating that Dex induces gender-specific programming of skeletal growth. Gender-specific programming is supported by measurement of cortical dimensions, including periosteal and endosteal circumferences and cortical thickness; these were altered in adult female but not male Dex-treated offspring. This observed sex difference might be explained by altered numbers of glucocorticoid receptors on cells in bone. However, we believe that a more likely explanation is through a central mechanism, including changes in number of various centrally located receptors. It has previously been demonstrated that in maternal glucocorticoid treatment programmes the HPA axis functions in a sex-specific manner and that these changes are associated with modification in corticosteroid receptor expression in the adult brain (Liu et al. 2001). The areal BMD of the long bones and the spine, as well as the trabecular and volumetric BMD, were unchanged in the Dex-treated offspring. Therefore, prenatal Dex exposure affects skeletal growth but not mineralization. Direct effects of mineralization in utero do not show as well, as there is not much mineralization so early in developing pups, but our indirect findings in programming is a way in which this might be studied.

Another mechanism for glucocorticoid-induced bone diseases arises from changes in osteoblasts and osteocytes number due to apoptosis of these cells (Hughes \& Boyce 1997. Weinstein et al. 1998, Weinstein \& Manolagas 2000). The lack of change in bone mineralization, seen in the present study, could be because glucocorticoids increase osteoclast apoptosis in rats and thereby counterbalance the effect of glucocorticoids on osteoblast apoptosis. In contrast, no effect on osteoclast apoptosis is seen in the human skeleton (Dempster et al. 1997).

The lack of change in bone mineralization seen in the present study could be due to effects of glucocorticoids on osteoclasts. Dempster et al. (1997) have shown that glucocorticoids increase BMD in the rat and that the effect is attributed to increased osteoclast apoptosis which is in sharp contrast to the effect on the human skeleton.

Glucocorticoids are known to exert direct and complex effects on chondrocytes and osteoblasts and are therefore able to affect bone formation (Chen \& Feldman 1979, Wong et al. 1990, Canalis 1996, Swolin et al. 1996, Klaus et al. 2000). Thus, the affected skeletal growth in male Dex-treated rats might involve direct effects on mesenchymal cells within the skeleton. Another possibility is that Dex may affect skeletal growth via a direct central effect on the brain and the HPA axis, as the time chosen for the Dex treatment corresponds to an early period when fetal brain development occurs in the rat (Nyrienda et al. 1998). It has previously been demonstrated that proper development of the fetal HPA axis is critical for normal growth and organ development. A third possibility is an indirect effect via the placenta or via hormones and growth factors in the pregnant dam. The observed effects may not be an effect of Dex but may be the result of changes in sensitivity to other hormones or the alteration in other factors as a result of Dex exposure.

Our study contributes to the investigation on the effects on skeletal growth and bone tissue in adult rat offspring. However, future studies are required to explore the complex effects and mechanisms of glucocorticoids on bone tissue after prenatal exposure, as the effect depends on the species, the duration of exposure, and the dose and time of exposure during pregnancy.

Leptin is involved in regulating food intake, energy balance, bone formation and neuroendocrine function. Increasing evidence indicates that leptin may play a role in fetal bone metabolism (Ogueh et al. 2000). Leptin has also been shown to have a potential role in endochondral ossification (Kume et al. 2002) and furthermore leptin reduces ovariectomy-induced bone loss in rats (Burguera et al. 2001). Recent data imply that leptin is involved in the central regulation of bone remodelling (Ducy et al. 2000) and the increased leptin levels in the present study may reflect a central mechanism for skeletal regulation. This idea is supported by a recent study demonstrating that 
skeletal growth is increased in $o b / o b$ mice (Steppan et al. 2000).

IGF-I is involved both in skeletal growth and in adult bone metabolism. IGF-I is regarded as an anabolic factor for bone formation (Canalis 1996). The proliferation of chondrocytes and the expression of IGF-I in the growth plate is affected by corticosteroids (Klaus et al. 2000). Furthermore, glucocorticoids have been shown to decrease the expression of IGF-I in human osteoblasts (Swolin et al. 1996). However, the affected skeletal growth in Dextreated offspring was not associated with any effect on serum levels of IGF-I at the times examined. Whether the IGF-I levels were affected at the time of exposure remains unknown.

In conclusion, prenatal Dex exposure affects skeletal growth in rats in a gender-specific manner, while the mineralization of bones is unaffected in both male and female offspring.

\section{Acknowledgements}

The laboratory assistance provided by Britt-Mari Larsson, Anette Hansevi and Maud Petterson is gratefully acknowledged, and we are grateful to Olle Vidal for helping with the $\mathrm{pQCT}$ technique. This study was supported by grants from the Swedish Foundation for Strategic Research, Lundberg Foundation, the Torsten and Ragnar Söderbergs Foundation, the Emil and Vera Cornell Foundation, Petrus and Augusta Hedlunds Foundation, the Swedish Association Against Rheumatic Disease, the Swedish Cancer Fund, the Novo Nordisk Foundation, Magnus Bergvalls Foundation, the Swedish Medical Research Council (project no. 12206, 7509), the Swedish Heart and Lung Foundation, the Wilhelm and Martina Lundgrens Foundation, the Åke Wibergs Foundation, the Svenska Läkaresällskapet Foundation, the SU Foundation, the Tore Nilssons Foundation and SWEGENE Center for Bio-Imaging, Gothenburg University.

\section{References}

Barker DJP, Hales CN, Fall CHD, Osmond C, Phipps K \& Clark PM 1993 Type 2 (non-insulin-dependent) diabetes mellitus, hypertension and hyperlipidaemia (syndrome $\mathrm{X}$ ): relation to reduced fetal growth. Diabetologia 36 62-67.

Benediktsson R, Lindsay R, Noble J, Seckl JR \& Edwards CRW 1993 Glucocorticoid exposure in utero: a new model for adult hypertension. Lancet 341 339-341.

Blodgett FM, Burgin I, Iezzoni D, Gribetz D \& Talbot NB 1956 Effects of prolonged cortisone therapy on the statural growth, skeletal maturation and metabolic status of children. New England Journal of Medicine 254 626-641.

Burguera B, Hofbauer LC, Thomas T, Gori F, Evans GL, Khosla S, Riggs BL \& Turner RT 2001 Leptin reduces ovariectomy-induced bone loss in rats. Endocrinology 142 3546-3553.

Canalis E 1996 Mechanisms of glucocorticoid action in bone: implication to glucocorticoid-induced osteoporosis. Journal of Clinical Endocrinology and Metabolism 81 3441-3447.
Chen T \& Feldman D 1979 Glucocorticoid receptors and actions in subpopulations of cultured rat bone cells. Journal of Clinical Investigation 63 750-758.

Clark PM 1998 Programming of the hypothalamo-pituitary-adrenal axis and the fetal origins of adult disease hypothesis. European Journal of Pediatrics 157 (Suppl) S7-S10.

Cushing H 1932 The basophil adenomas of the pituitary body and their clinical manifestations (pituitary basophilism). Bulletin of the Johns Hopkins Hospital 50 137-195.

Dahlgren J, Nilsson C, Jennische E, Ho H-P, Eriksson E, Niklasson A, Björntorp P, Albertsson-Wikland K \& Holmäng A 2001 Prenatal cytokine exposure results in obesity and gender-specific programming. American Journal of Physiology, Endocrinology and Metabolism 281 E326-E334.

Dempster DW, Moonga BS, Stein LS, Horbert WR \& Antakly T 1997 Glucocorticoids inhibit bone resorption by isolated rat osteoclasts by enhancing apoptosis. Journal of Endocrinology 154 397-406.

Ducy P, Amling M, Taked, S, Priemel M, Schilling AF, Beil FT, Shen J, Vinson C, Rueger JM \& Karsenty G 2000 Leptin inhibits bone formation through a hypothalamic relay: a central control of bone mass. Cell 100 197-207.

Gale CR, Martyn CN, Kellingray S, Eastell R \& Cooper C 2001 Intrauterine programming of adult body composition. Journal of Clinical Endocrinology and Metabolism 86 267-272.

Hofbauer LC, Gori F, Riggs BL, Lacey DL, Dunstan CR, Spelsberg TC \& Khosla S 1999 Stimulation of osteoprotegerin ligand and inhibition of osteoprotegerin production by glucocorticoids in human osteoblastic lineage cells: potential paracrine mechanisms of glucocorticoid-induced osteoporosis. Endocrinology 140 4382-4389.

Hofman PL, Cutfield WS, Robinson EM, Bergman RN, Menon RK, Sperling MA \& Gluckman PD 1997 Insulin resistance in short children with intrauterine growth retardation. Journal of Clinical Endocrinology and Metabolism 82 402-406.

Holmäng A 2001 Perinatal origin of adult disease. Scandinavian Cardiovascular Journal 35 178-185.

Hughes DE \& Boyce BF 1997 Apoptosis in bone physiology and disease. Molecular Pathology 50 132-137.

Klaus G, Jux C, Fernandez P, Rodriguez J, Himmele R \& Mehls O 2000 Suppression of growth plate chondrocyte proliferation by corticosteroids. Pediatric Nephrology 14 612-615.

Kume K, Satomura K, Nishisho S, Kitaoka E, Yamanouchi K, Tobiume S \& Nagayama M 2002 Potential role of leptin in endochondral ossification. Journal of Histochemistry and Cytochemistry 50 159-169.

Liu L, Li A \& Matthews G 2001 Maternal glucocorticoid treatment programs HPA regulation in adult offspring: sex-specific effects. American Journal of Physiology, Endocrinology and Metabolism 280 E729-E739.

Lucas A 1991 Programming by early nutrition in man. In The Childhood Environment and Adult Disease, 156, pp 38-50. Eds GR Boc \& J Whelan. Chichester, UK: John Wiley and Sons.

Matthews SG 2000 Antenatal glucocorticoids and programming of developing CNS. Pediatric Research 47 291-300.

Mosier HD, Dearden LC, Roberts RC, Jansons RA \& Biggs CS 1981 Regional differences in the effects of glucocorticoids on maturation of the fetal skeleton of the rat. Teratology 23 15-24.

NIH 1995 NIH Consensus Development Conference. Effect of corticosteroids for fetal maturation and perinatal outcomes. American Journal of Obstetrics and Gynecology 173 253-344.

Nyrienda MJ, Lindsay RS, Kenyon CJ, Burchell A \& Seckl JR 1998 Glucocorticoid exposure in late gestation permanently programs rat hepatic phosphoenolpyruvate carboxykinase and glucocorticoid receptor expression and causes glucose intolerance in adult offspring. Journal of Clinical Investigation 101 2174-2181.

Ogueh O, Sooranna S, Nicolaides KH \& Johnson MR 2000 The relationship between leptin concentration and bone metabolism in 
the human fetus. Journal of Clinical Endocrinology and Metabolism $\mathbf{8 5}$ 1997-1999.

Ornoy A \& Altshuler G 1976 Maternal endotoxemia, fetal anomalies, and central nervous system damage: a rat model of a human problem. American Journal of Obstetrics and Gynecology 124 196-204.

Paxinos G, Törk I, Tecott LH \& Valentino KL 1991 Atlas of the Developing Rat Brain. London: Academic Press.

Robinson S, Walton RJ, Clark PM, Barker DJ, Hales CN \& Osmond C 1992 The relation of fetal growth to plasma glucose in young men. Diabetologia 35 444-446.

Smith MS, Freeman ME \& Neill JD 1975 The control of progesterone secretion during the estrous cycle and early pseudopregnancy in the rat: prolactin, gonadotropin and steroid levels associated with rescue of the corpus luteum of pseudopregnancy. Endocrinology 96 219-226.

Steppan CM, Crawford DT, Chidsey-Frink KL, Ke H \& Swick AG 2000 Leptin is a potent stimulator of bone growth in ob/ob mice. Regulatory Peptides 25 73-78.

Swolin D, Brantsing C, Matejka G \& Ohlsson C 1996 Cortisol decreases IGF-I mRNA levels in human osteoblast-like cells. Journal of Endocrinology 149 397-403.
Weinstein RS \& Manolagas SC 2000 Apoptosis and osteoporosis. American Journal of Medicine 108 153-164.

Weinstein RS, Jilka RL, Parfitt M \& Manolagas SC 1998 Inhibition of osteoblastogenesis and promotion of apoptosis of osteoblasts and osteocytes by glucocorticoids. Journal of Clinical Investigation $\mathbf{1 0 2}$ 274-282.

Windahl SH, Vidal O, Andersson G, Gustafsson JA \& Ohlsson C 1999 Increased cortical bone mineral content but unchanged trabecular bone density in female ER beta $(-/-)$ mice. Journal of Clinical Investigation 104 895-901.

Wong M-M, Rao LG, Ly H, Hamilton L, Tong J, Sturtridge W, McBroom R, Aubin JE \& Murray TM 1990 Long-term effects of physiological concentration of dexamethasone on human bone-derived cells. Journal of Bone and Mineral Research 5 803-813.

Received in final form 9 May 2002

Accepted 23 May 2002 